\title{
Patrones de ergatividad en el español peninsular
}

\author{
Victor Lara
}

\begin{abstract}
Western Peninsular Spanish possesses a type of causative construction in which an intransitive lexeme is used as transitive. Specifically, the verbs caer ('to fall'), quedar ('to stay') and entrar ('to enter) can induce a direct object in detriment of the standard verbs tirar ('to throw'), dejar ('to leave') and meter ('to put in'). This phenomenon (called lability) has not been investigated in depth for Spanish and, with this paper I attempt to pinpoint its current geographical extension as well as the semantic factors that favour the transitivisation of these verbs.
\end{abstract}

Keywords: Causativisation, transitivisation, lability, Peninsular Spanish, ergativity.

\section{Introducción}

En este artículo, nos proponemos ofrecer un primer panorama sobre la variación gramatical que se manifiesta en el español peninsular dentro de una serie de construcciones causativas, en las que ciertos verbos inacusativos se pueden emplear de manera transitiva. El español estándar es capaz de expresar causa mediante distintas estrategias, siendo las principales una construcción perifrástica con el verbo hacer más un infinitivo (1); y los pares léxicos, uno de los cuales expresa causa y el otro, efecto (2). Igualmente, el español cuenta con una construcción formada por un reflexivo ( $\mathrm{se}$ ) más un verbo conjugado y un dativo experimentante. Esta estrategia se usa sobre todo para dar un matiz de falta de volición por parte del autor de la acción (3).

Le hice ver la película, aunque no quería

(2 a) Tiré el vaso - El vaso (se) cayó

b) Dejé los libros en la mesa - Los libros (se) quedaron en la mesa

c) Metí el coche en el garaje - El coche entró en el garaje

Se me cayó el vaso mientras caminaba

Sin embargo, algunas variedades del español peninsular modifican la estrategia léxica utilizando el lexema intransitivo para expresar también causa (4):

(4) a) Caí el vaso

b) (Me) quedé los libros en la mesa

c) Entré el coche en el garaje 
La posibilidad de construir bajo el mismo lexema tanto una lectura transitiva como intransitiva se denomina labilidad y, en consecuencia, este tipo de verbo se llama lábil (nos centraremos en este fenómeno más adelante). En este artículo, intentaremos pues mostrar su distribución actual y las causas semánticas.

\section{Estado de la cuestión}

El uso transitivo de estos verbos intransitivos en el español no se ha investigado en profundidad, ya que la bibliografía tan solo se dedica a delimitar su extensión geográfica. Concretamente, Zamora Vicente (1970), Alvar (1996), Montero (2006), Ariza (2008) y la Real Academia Española (RAE) (2009) aseguran que esta situación se manifiesta en las provincias de Burgos, León, Ávila, Zamora, Salamanca, Valladolid, Cáceres, Badajoz, Toledo y Ciudad Real (mapa 1).

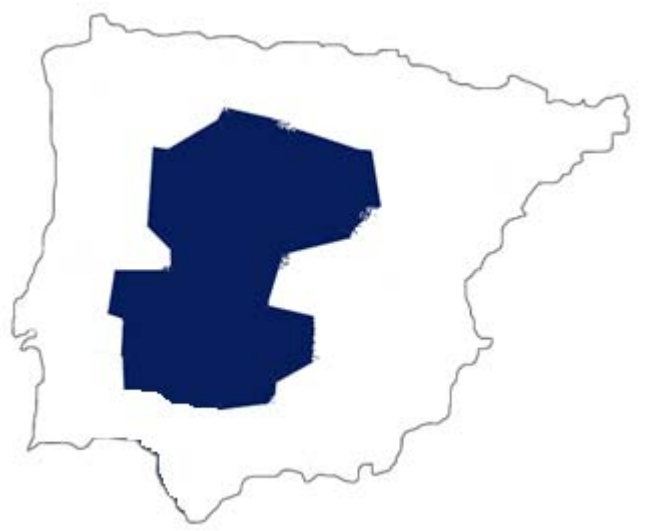

Mapa 1. Extensión del fenómeno, según la bibliografía.

Además, Jiménez Fernández \& Tubino Blanco (2014) afirman que también puede surgir en Andalucía, pero no tendremos en consideración sus postulados debido a las siguientes razones: en primer lugar, su análisis no se aplica a datos recogidos ni a ocurrencias sacadas de algún trabajo de campo, por lo que ignoramos el origen de las frases que ejemplifican; en segundo lugar, entienden que el dialecto andaluz es uniforme. Alvar (1996), Frago (1993), Narbona (2003), Mondéjar (1991), Penny (2004) o Fernández-Ordóñez (2011) han demostrado que, lingüísticamente, Andalucía se puede dividir nítidamente en este - oeste. Ambas zonas se caracterizan por particularidades fonéticas, morfológicas y sintácticas de distinta índole. Solo ciertas regiones centrales comparten patrones de ambos lados. Ello vuelve a poner en duda el origen o la validez de las oraciones que proveen en su artículo. No obstante, volveremos sobre algunos puntos interesantes de su estudio más adelante. 
A pesar de los esfuerzos por cartografiar el alcance de este fenómeno, la bibliografía mencionada no ha logrado proporcionar una explicación lingüística ni una investigación pormenorizada sobre el empleo real de estos verbos en lecturas transitivas. La única referencia a una posible razón lingüística se puede hallar en Montero (2006). Sin embargo, esta autora apenas dedica un par de líneas a sugerir que la labilidad aparece en acciones involuntarias, aunque esta posibilidad solo se aplicaría al verbo caer. Según ella (y siempre como una conjetura más que como un análisis exhaustivo), la diferencia semántica entre (5) y (6) consiste en el hecho de que el último, a diferencia del primero, surge para expresar una acción voluntaria causada por el agente.

(5) Caí el vaso

(6) Tiré el vaso

No obstante, el español ya posee una estrategia bastante común para expresar falta de volición, como indica (3). La hipótesis de Montero no aclara las diferencias entre (3) y (5), así como los posibles factores que entran en juego en la transitivización de los verbos entrar y quedar.

Asimismo, si se realiza una búsqueda más precisa en los distintos atlas lingüísticos y en ciertos corpus dialectales (ALCyL, ALEANR, Alec-Man y COSER) de los que disponemos hoy en día, comprobamos que el fenómeno de la labilidad se atestigua en los mismos lugares que la bibliografía a la que nos referíamos más arriba mencionaba. Es más, algunos autores incluso sostienen que el empleo de la forma lábil está más extendido en ciertos verbos que en otros. Concretamente, Alvar (1996), Ariza (2008) y García Mouton (1994) afirman que entrar es el verbo causativizado más difundido, mientras que caer y quedar se encuentran en áreas más restringidas. Además, caer se daría en menor medida que quedar.

El fenómeno de la labilidad no se constriñe al español de la Península Ibérica. El catalán y el portugués presentan casos análogos, en principio, con el par léxico morir - matar (Said 1931; Nunes 1945; Wheeler et al. 1999). Aunque muchas lenguas tienen el patrón de la labilidad (nos referiremos a estudios específicos más adelante), la mayoría de ellas detransitiviza los verbos para emplearlos también como intransitivos. En otras palabras, la mayoría de idiomas, cuando aplican la labilidad, suelen transformar los verbos transitivos en intransitivos. El caso del español presenta el efecto contrario: un verbo intransitivo se emplea de manera transitiva a pesar de que ya exista un lexema transitivo para expresar la misma causa. Con el fin de comprender los factores semánticos que inciden en este fenómeno, amén de la vigencia geográfica actual, hemos llevado a cabo un trabajo de campo, cuya metodología pasamos a explicar a continuación. 


\section{Metodología}

El trabajo de campo realizado ha abarcado los enclaves expuestos en el mapa 2 y la tabla 1, en consonancia con las áreas a las que la bibliografía aludía (mapa 1).

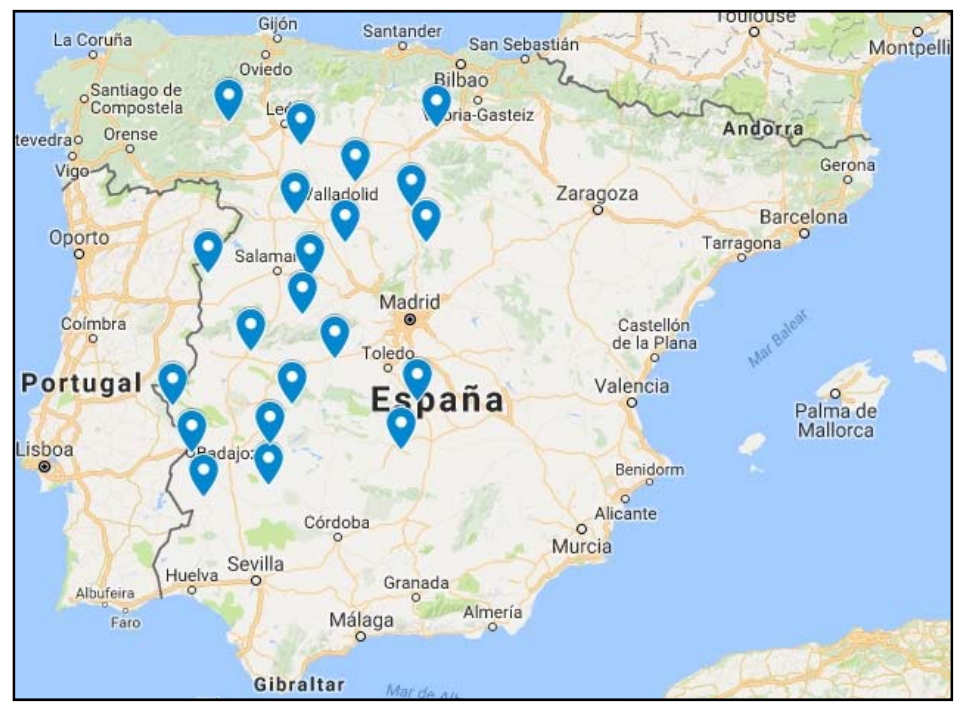

Mapa 2. Trabajo de campo.

\begin{tabular}{|l|l|}
\hline Provincia & Localidades \\
\hline León & León, Bembibre \\
\hline Zamora & Toro \\
\hline Valladolid & Olmedo \\
\hline Segovia & Riaza \\
\hline Salamanca & Lumbrales, Peñaranda de Bracamonte \\
\hline Palencia & Villmuriel de Cerrato \\
\hline Ávila & Piedrahíta \\
\hline Burgos & Aranda de Duero, Briviesca \\
\hline Toledo & Consuegra, Talavera de la Reina \\
\hline Ciudad Real & Pozuelo de Calatrava \\
\hline Cáceres & Guadalupe, Valencia de Alcántara, Plasencia \\
\hline Badajoz & Badajoz, Valle de Santa Ana, Bienvenida, Villanueva de la Serena \\
\hline
\end{tabular}

Tabla 1. Localidades de la encuesta.

Como se trata de un fenómeno no estándar, hemos encuestado a hablantes con bajo nivel educativo, puesto que representan el perfil social que más tiende a mantener fenómenos vernáculos o no estándares. En la tabla 2, detallamos el número de informantes así como las ocurrencias que hemos obtenido. 


\begin{tabular}{|c|c|}
\hline Informantes & Ocurrencias \\
\hline 200 & 1.938 \\
\hline
\end{tabular}

Tabla 2. Datos de la encuesta.

El método que hemos empleado ha tratado de no condicionar al hablante. Debido a la dificultad que entraña registrar la aparición de este fenómeno durante una entrevista semidirigida, una entrevista sociolingüística u otro tipo de estrategias de preguntas indirectas que carecen de espontaneidad (Gilquin 2010), hemos filmado una serie de escenas en las que se ve a una persona realizando una serie de actividades que implican el uso de los verbos que estudiamos. A los hablantes se les pedía que describieran espontáneamente las escenas que visualizaban. Cada una de ellas preveía un par léxico distinto, teniendo en cuenta distintos tipos de pacientes y agentes. En la tabla 3, detallamos el número de escenas por cada par léxico y los matices semánticos previstos.

\begin{tabular}{|c|c|c|c|}
\cline { 2 - 4 } \multicolumn{1}{c|}{} & Entrar & Quedar & Caer \\
\hline Agente humano voluntario & 6 de 10 & 4 de 10 & 4 de 10 \\
\hline Agente humano involuntario & 2 de 10 & 4 de 10 & 4 de 10 \\
\hline Agente no humano & 2 de 10 & 2 de 10 & 2 de 10 \\
\hline
\end{tabular}

Tabla 3. Número de escenas del trabajo de campo.

Para aclarar la dinámica de la encuesta, presentamos un extracto de la transcripción de dos escenas diversas.

Entrevistador: Dígame qué ocurre en esta escena, ¿qué hace la chica que está usted viendo?

[Vemos una chica que aparece en una oficina, camina hasta un sillón que tiene una botella encima de uno de sus reposabrazos, se sienta y, sin querer, tira la botella. La chica se da cuenta, se agacha a recoger la botella y la deja en la mesa que tiene enfrente]

Entrevistado: La chica está caminando..., se sienta... y cae la botella. Ahora la coge. La pone en la mesa y se vuelve a apoyar en el sillón.

Entrevistador: Dígame qué pasa en esta escena, ¿qué hace la chica que está usted viendo?

[Vemos a la misma chica que está trabajando. Mira el reloj y decide irse. Coge todas sus pertenencias, pero se olvida de las gafas de sol. Cuando sube las escaleras, se toca la cabeza, como si buscara algo, y se da cuenta de que se ha dejado las gafas de sol en la oficina] 
Entrevistado: Aquí está la misma chica..., parece que está trabajando...., ahora está mirando el reloj, se levanta, se va, está harta de trabajar... coge sus cosas... ah, se queda las gafas en la mesa..., ¿ves? Ahora se da cuenta de que se ha quedado las gafas en la mesa.

En resumen, este modus operandi ha permitido un análisis cualitativo y cuantitativo en la producción de ejemplos del fenómeno de la causativización, por lo que pasamos a describir y analizar los resultados en los siguientes epígrafes.

\section{Resultados}

\subsection{Distribución geográfica}

En primer lugar, es necesario resaltar que los resultados obtenidos en el trabajo de campo muestran que el fenómeno en estudio se da en todas las edades y en todos los géneros encuestados, pero sería de gran utilidad ampliar la investigación a hablantes cultos, para verificar la extensión social del mismo. Asimismo, hemos podido cartografiar la difusión espacial que los tres pares léxicos ocupan en la actualidad gracias al programa GabMap (Nerbonne et al. 2010).

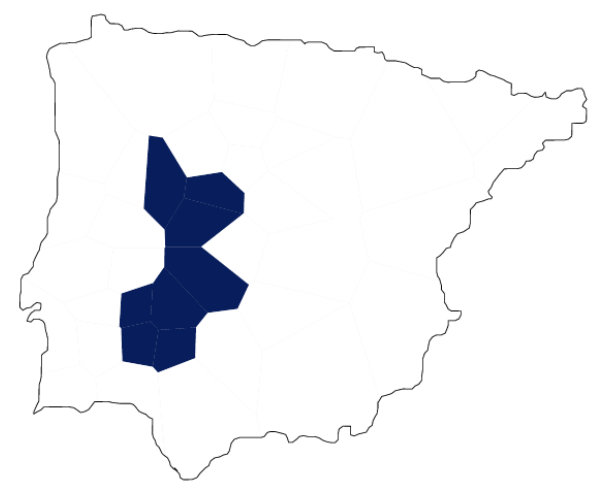

Mapa 3. Extensión actual de caer.

Si comparamos los mapas 3, 4 y 5 con el mapa 1, advertimos un descenso drástico de la extensión geográfica en lo que respecta al fenómeno de la labilidad. Por un lado, no hemos hallado ocurrencias en Burgos, el sur de Valladolid, Segovia y León. Asimismo, el área de Toledo que limita con Ávila no ha proporcionado ejemplos de este fenómeno tampoco y es en el este de Extremadura donde el comportamiento vernáculo empieza a perderse. Igualmente, su incidencia en la zona de Zamora ha sido menor que por todo Salamanca, Cáceres o Badajoz: provincias que han dado el mayor número de ocurrencias. 


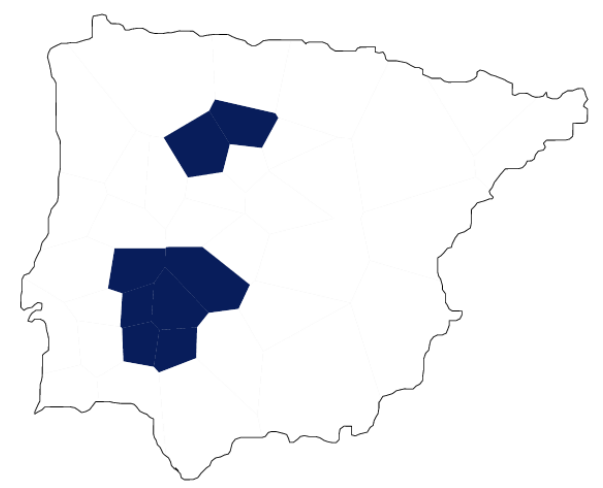

Mapa 4. Extensión actual de quedar.

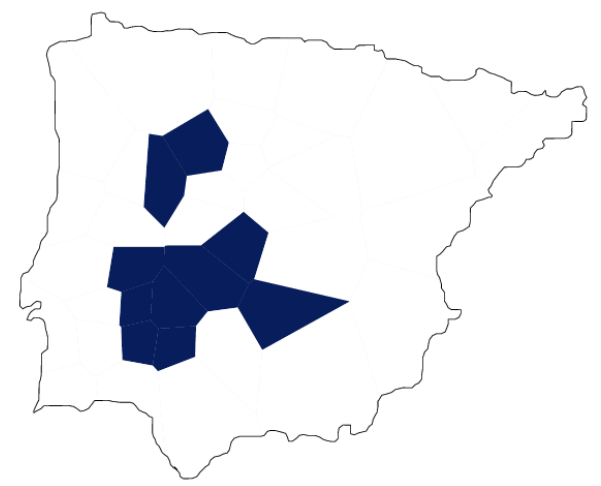

Mapa 5. Extensión actual de entrar.

Por tanto, los apuntes hechos por la bibliografía tienen que actualizarse, teniendo en cuenta la reducción geográfica tan extrema a áreas más occidentales; en concreto, del sur de Zamora hasta Andalucía occidental. A continuación, detallamos en la tabla 4 la cantidad de informantes que han producido el fenómeno lábil y los que no.

\begin{tabular}{|c|c|c|c|}
\cline { 2 - 4 } \multicolumn{1}{c|}{} & Entrar & Quedar & Caer \\
\hline Lábil & $80(40 \%)$ & $62(31 \%)$ & $38(19 \%)$ \\
\hline No lábil & $120(60 \%)$ & $138(69 \%)$ & $162(81 \%)$ \\
\hline Total & $200(100 \%)$ & $200(100 \%)$ & $200(100 \%)$ \\
\hline
\end{tabular}

Tabla 4. Número de informantes y su comportamiento lingüístico. 
La tabla 4 muestra que el empleo lábil más difundido se corresponde con el verbo entrar, seguido de quedar y caer en último lugar.

Pese a que la extensión de los verbos entrar y quedar empieza a ser desplazada por el patrón estándar, es el primero de ellos (entrar) el que abarca zonas más orientales. La opción de quedar en lugar de dejar es la más extendida en el norte, mientras que caer en vez de tirar recorre ininterrumpidamente las zonas a lo largo de la ruta de la plata, desde el sur de Zamora hasta Andalucía occidental. El patrón de difusión responde al modelo por ondas (Wolfram \& Schilling-Estes 2003), ya que los enclaves urbanos no han sido más estándares que los rurales; en otras palabras, la demografía de la localidad no ha intervenido en la difusión geográfica de la labilidad. Este hecho también se puede observar por las áreas residuales que la difusión del modelo estándar ha provocado. En conclusión, este fenómeno se ha reducido y el patrón normativo empieza a ser más común.

En general, la extensión geográfica de la labilidad recorre ininterrumpidamente la ruta de la plata fundada por los romanos, la cual ha funcionado siempre de vía de comunicación en España hasta el presente (mapa 6).

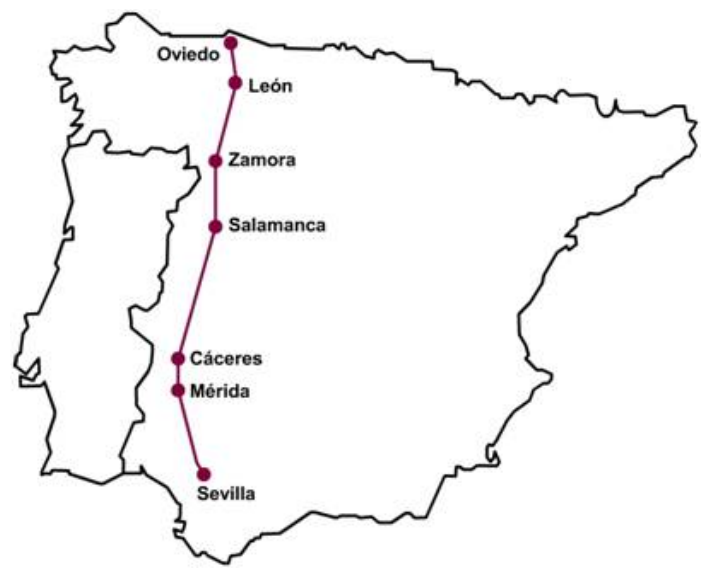

Mapa 6. Ruta de la plata.

De hecho, la región en la que este fenómeno se manifiesta fue repoblado por leoneses y castellanos de la parte occidental, a quienes se les otorgaron tierras a cambio de su establecimiento en los territorios que se acababan de conquistar (Cano 2004, Menéndez Pidal 2005). Sus características lingüísticas se exportaron $\mathrm{y}$, actualmente, toda esta área comparte una serie de particularidades que solo se pueden explicar por esta repoblación y la comunicación y el contacto que siempre han mantenido. Concretamente, el español peninsular occidental se caracteriza por confundir los pronombres átonos de tercera persona. Mientras que el español estándar elige el caso para elegir el clítico, el español peninsular occidental suele seleccionar el clítico en base a la animacidad, la definitud o la oposición entre 
contable e incontable (Fernández-Ordóñez 1999) (nos referiremos a este fenómeno más adelante). Incluso la morfología de ciertos pronombres clíticos, como vos en vez del estándar os, se da en esta zona (Lara 2012), así como la pronunciación de velares, la velarización de /n/ (Cano 2004; Menéndez Pidal 2005) o el uso de tiempos presentes para expresar futuro (Lara 2016). Fernández-Ordóñez (2011) también ha comprobado que el desarrollo del español peninsular depende de la generalización de distintos patrones que se esparcen de dos maneras distintas: de este a oeste y viceversa (sobre todo en lo referente a la morfosintaxis) o de norte a sur y, hasta cierto punto, viceversa (sobre todo en la fonética). Así, el español peninsular occidental, de acuerdo con la autora, representa un bloque dialectal que comparte particularidades específicas que de vez en cuando se han podido generalizar también al resto del español peninsular.

En el siguiente subcapítulo, describiremos el comportamiento semántico de los resultados obtenidos.

\subsection{Distribución semántica}

En la tabla 4, proporcionamos el número de informantes que produjeron la labilidad en los diferentes verbos en estudio. Sin embargo, si aplicamos un análisis más exhaustivo, advertimos que el surgimiento del verbo lábil se restringe a ciertos matices semánticos. Estos matices han provocado que el informante exprese la labilidad en ciertos casos, recurra al lexema transitivo estándar en otros o se comporte coherentemente a la hora de elegir solo la labilidad. Centrémonos ahora en observar la distribución cartográfica de la labilidad según los factores semánticos (mapas 7-12).

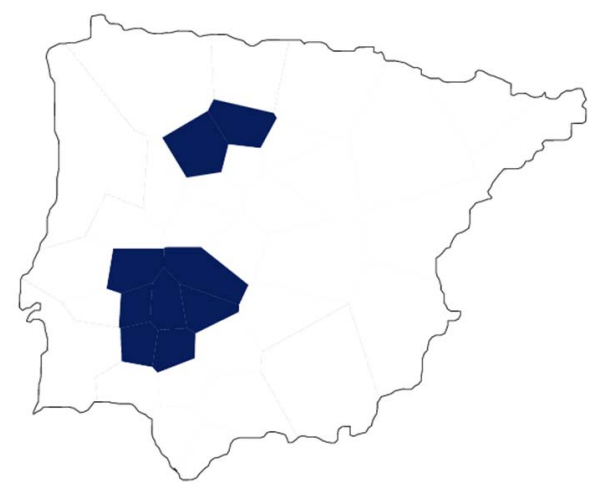

Mapa 7. Quedar involuntario.

El mapa 7 muestra que toda la extensión del verbo quedar como lábil coincide al menos con el rasgo de un agente involuntario (7-8). 
(7) Se ha quedado las gafas en la mesa

(8) Ha quedado la luz encendida

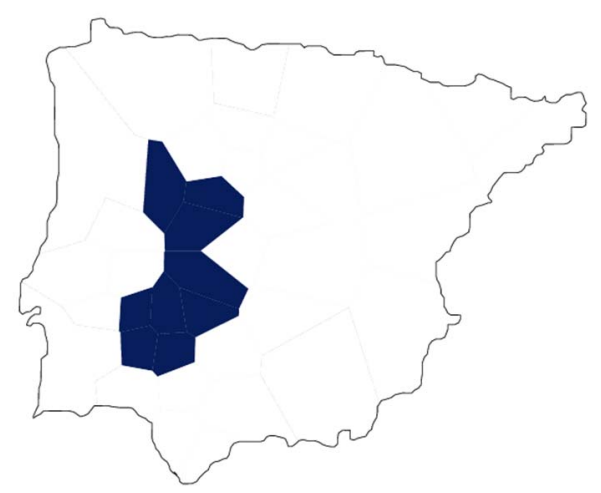

Mapa 8. Caer involuntario

Asimismo, el mapa 8 presenta la distribución del verbo caer como lábil de acuerdo con una lectura involuntaria y, al igual que el mapa 7, toda la extensión de este verbo como transitivo se da, al menos, con esta lectura (9-10).

(9) La chica ha caído el vaso sin querer

(10) Ha caído la botella al sentarse

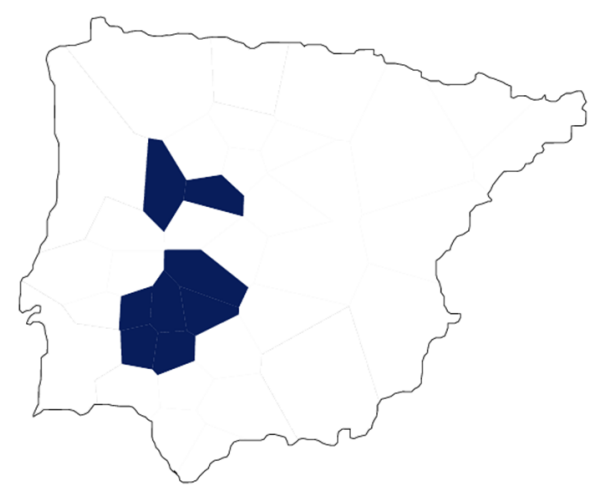

Mapa 9. Caer agente no humano.

Además, el mapa 9 demuestra que el uso de caer por tirar posee una distribución ligeramente más pequeña, en concreto en oraciones con un sujeto inanimado (11).

(11) El viento ha caído la calabaza 


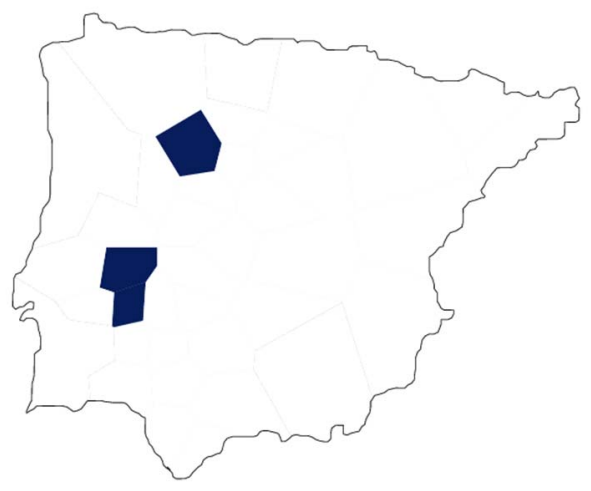

Mapa 10. Quedar voluntario.

El mapa 10 dibuja una distribución más reducida, ya que solo dos zonas dentro del área de quedar por dejar se caracterizan por tener también una lectura volitiva (12).

(12) La chica ha decidido quedar los libros en la mesa

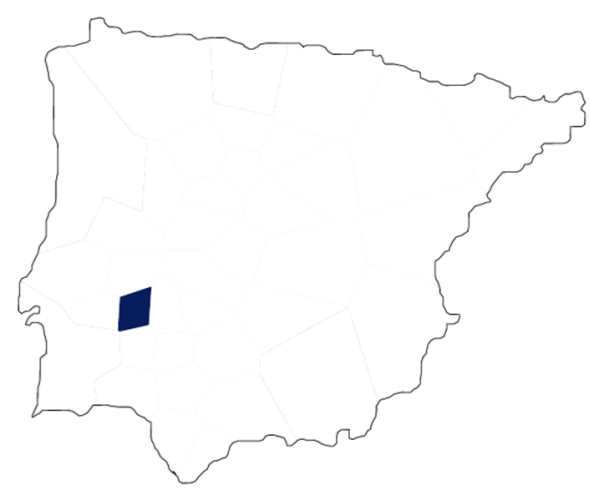

Mapa 11. Caer voluntario.

El mapa 11 muestra que, en el caso de caer, la acción intencionada solo se documenta en un área que se ubica dentro de la zona donde el uso transitivo es involuntario. Sin embargo, la lectura volitiva ha hecho que el fenómeno se reduzca drásticamente (13-14).

(13) La chica ha cogido el vaso y lo ha caído

(14) ¿Cómo que qué ha hecho? Caerla [la botella] 


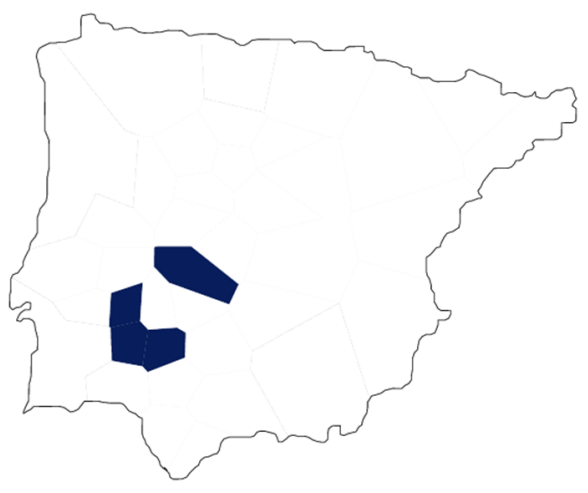

Mapa 12. Entrar lecturas télicas.

En el caso de entrar, los matices que aluden a la animacidad o volición no han revelado ninguna significatividad. En cambio, el hecho de tener una oración télica hace que el fenómeno se reduzca, pues tan solo se localiza en la parte más suroccidental (15).

(15) Ha entrado el folio en el sobre

Si cotejamos los mapas 3 a 5 con los mapas 7 a 12, nos damos cuenta de que la labilidad decrece o se incrementa según la lectura semántica. Como consecuencia, las acciones involuntarias tienden más a provocar la labilidad frente a las voluntarias. Esto quiere decir que hay informantes que producen tanto la labilidad como el patrón normativo a la vez y que dicha producción está estrechamente ligada a los matices que hemos aludido. La tabla 5 nos aclara el comportamiento de cada verbo.

\begin{tabular}{|c|c|c|c|c|c|}
\hline & Caer & & Quedar & & Entrar \\
\hline Involuntario & $\begin{array}{c}38 \\
(100 \%)\end{array}$ & Involuntario & $\begin{array}{c}62 \\
(100 \%)\end{array}$ & Atélico & $\begin{array}{c}80 \\
(100 \%)\end{array}$ \\
\hline $\begin{array}{l}\text { Agente no } \\
\text { humano }\end{array}$ & $\begin{array}{c}29 \\
(76,3 \%)\end{array}$ & $\begin{array}{l}\text { Agente no } \\
\text { humano }\end{array}$ & $\begin{array}{c}51 \\
(82,25 \%)\end{array}$ & Télico & $\begin{array}{c}17 \\
(21,25 \%)\end{array}$ \\
\hline Voluntario & $8(21 \%)$ & Voluntario & $\begin{array}{c}13 \\
(20,9 \%)\end{array}$ & & \\
\hline
\end{tabular}

Tabla 5. Número de informantes y la labilidad, según los matices semánticos relevantes.

La tabla 5 demuestra que los informantes que emplea la labilidad no lo hacen en todos los casos. De hecho, todos ellos la usan en sujetos no volitivos (en los casos 
de quedar y caer) y oraciones atélicas (en el caso de entrar). Pero estos mismos informantes han elegido para el resto de matices semánticos ya sea la labilidad o el lexema transitivo normativo (meter, tirar y dejar) (16-20).

(16) La chica coge la botella y la tira a la papelera

(17) La chica coge el vaso y lo tira al suelo

(18) Al final deja los libros en la mesa y se va

(19) Mete el papel en el sobre

(20) Mete los folios en el archivador

Si se analizan estos ejemplos, parece claro que, en el caso de tirar, el agente ha llevado a cabo la acción de manera intencionada (16-17). Es el mismo comportamiento que los informantes tienen al elegir dejar (18), mientras que meter surge en contextos télicos (19-20).

Por último, cuando comparamos todos los mapas, podemos advertir distintos continuum lingüísticos. De acuerdo con los resultados, los informantes que transitivizan caer también lo hacen con quedar y entrar (i).

(i) Entrar $>$ quedar $>$ caer

La jerarquía en (i) se explica de la siguiente manera: si un hablante causativiza el verbo quedar, también lo hace con entrar, pero aún no con caer. La transitivización de un verbo de la jerarquía implica la transitivización de los que se hallan a su izquierda, pero no a su derecha. Este mismo continuum puede cartografiarse en el mapa 13.

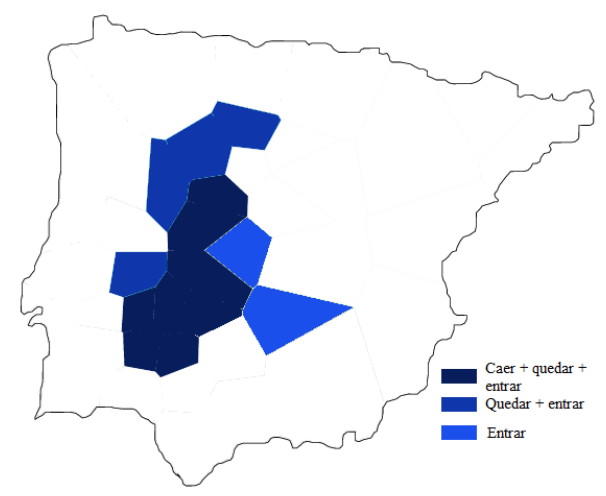

Mapa 13. Continuum en la caustaivización vernácula.

Asimismo, como la estrategia de la labilidad está sometida a factores semánticos, estos pueden ordenarse de la siguiente forma (ii-iii): 
(ii) agente humano involuntario $>$ agente no humano $>$ agente humano voluntario (iii) atélico $>$ télico

Las jerarquías que reproducimos en (ii) y (iii) indican que el informante que utiliza cualquiera de los tres verbos de manera lábil en oraciones con un sujeto agente no humano, también lo hace en oraciones en los que el sujeto es humano e involuntario. Además, si recurre a la labilidad en lecturas télicas, también lo hará en oraciones atélicas (15). Las jerarquías son implicativas y la estrategia de la labilidad siempre va de izquierda a derecha.

En el siguiente epígrafe, nos centraremos en el análisis lingüístico de los resultados que hemos presentado en esta sección.

\section{Análisis}

A continuación, analizaremos los resultados del trabajo de campo desde una perspectiva tipológica. En primer lugar, trataremos la aparición y desarrollo de la labilidad y los factores que fomentan la transitivización y causativización; posteriormente, discutiremos sobre la tendencia a la intransitividad escindida del español y, por último, defenderemos que el español peninsular occidental se caracteriza por la ergatividad escindida.

\subsection{Estrategias causativas: labilidad}

El fenómeno de la labilidad en el español peninsular occidental no es un caso aislado. En principio, las construcciones causativas a nivel universal se pueden expresar mediante tres formas diversas: la analítica (como el uso del verbo hacer más un infinitivo); la morfológica, en la que un verbo intransitivo adopta ciertos afijos que denotan causa (en turco, $\ddot{o l}$, 'morir' puede adquirir un afijo y convertirse en öl-dür, 'matar'); y los pares léxicos, con un lexema transitivo que expresa causa y uno intransitivo para el efecto (Comrie 1981). Sin embargo, la estrategia léxica a veces se expresa mediante el empleo de un mismo lexema que se escoge tanto para oraciones transitivas como intransitivas. Es a esto a lo que se le denomina labilidad (Haspelmath 1993; Letuchiy 2004; 2009) y es relativamente común. El recurso de la labilidad ha llamado menos la atención a los lingüistas que el resto de construcciones causativas (de hecho, la mayoría de la bibliografía se ha centrado en la alternancia entre incoativo / resultativo, como en inglés I broke the vase / the vase broke (Aikhenvald \& Dixon 2000; Shibatani 1976)), pero existen ciertos estudios que pueden ayudarnos a entender la situación del español peninsular occidental.

En primer lugar, hemos de saber qué tipo de labilidad es la del español. Letuchiy (2009) establece una tipología de los distintos tipos de verbos lábiles y 
distingue los siguientes: anticausativos, reflexivos, recíprocos, pasivos y conversos. Según dicha tipología, los verbos en $(4 \mathrm{a}-\mathrm{c})$ parecen encajar con los anticausativos, cuya labilidad preserva el paciente (patient-preserving). El comportamiento desigual según la semántica del sujeto en la labilidad lo ha tratado Creissels (2014), quien clasifica los verbos lábiles entre los que preservan el agente (agent-preserving / A-alignment) (21) y los que preservan el paciente (patient-preserving / P-alignment) (22).
(21) John drinks
John beber.3SG.PRS.
('John bebe (té)')
$\begin{array}{lllll}\text { (22) I } & \text { broke } & \text { the vase / The vase } & \text { broke } \\ & 1 \mathrm{SG} . & \text { romper.PST. } & \text { el jarrón / el jarrón } & \text { romper.PST }\end{array}$ ('Rompí el jarrón' / 'El jarrón se rompió’)

Mientras que (21) posee el mismo sujeto (siempre el agente), una de las alternativas de (22) muestra un sujeto paciente. Los casos del español se correlacionan claramente con el modelo P-alignment, ya que el verbo intransitivo surge para connotar la falta de volición del sujeto. Es más, la semántica del verbo y la de sus argumentos es crucial para la aparición, desarrollo y posterior pérdida de la labilidad. No es sorprendente que el español tenga este fenómeno, igual que otras lenguas (relacionadas o no entre sí) poseen un grado mayor o menor de labilidad. Prácticamente todos los artículos que tratan de ello indican que los verbos de movimiento o cambio de estado son los más propensos a ser lábiles (véase Kulikov \& Lavidas 2014; Jiménez Fernández \& Tubino Blanco 2014; Letuchiy 2004; 2015).

Igualmente, en lo que respecta a la posibilidad de transformar un verbo en lábil, los factores de volición y agentividad suelen también ser vitales (Van Valin 1990; Larjavaara 2000). Si se analizan los ejemplos de labilidad en el español peninsular occidental, descubrimos que los informantes que la producen lo empiezan a hacer en agentes no volitivos o en sujetos que carecen de agentividad (7-10). Una vez que la labilidad se establece en estas lecturas semánticas, se esparce a sujetos agentivos y volitivos (12-14).

Quizá debido a estas características, los verbos de logro son los más propensos a desarrollar labilidad, como sostiene Van Valin (1990). Es más, los tres verbos afectados en español se corresponden con verbos de logro y los verbos intransitivos que se han transitivizado tanto en francés estándar (sortir 'salir', apprendre 'aprender') (23-26) como en francés dialectal (tomber 'caer') pertenecen a esta clasificación (27-28).

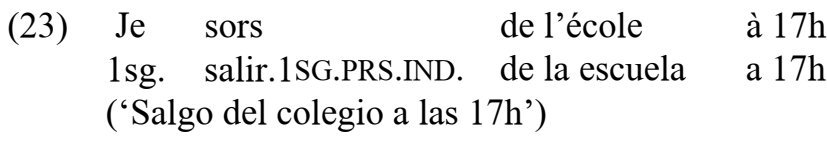


(24)

Je sors la pouvelle tous les jours

1sg. salir.1SG.PRS.IND. la basura todos los días

('Saco la basura todos los días')

$\begin{array}{llll}\text { J' } & \text { apprends } & \text { parler } & \text { l'anglais } \\ \text { 1sg. } & \text { aprender.1SG.PRS.IND. } & \text { hablar.INF. } & \text { el inglés }\end{array}$

('Aprendo a hablar inglés')
Le professeur m' apprend
parler
l'anglais
El profesor ACC. 1SG. aprender.3SG.PRS.IND. hablar.INF. el inglés
('El profesor me enseña a halar inglés')

$\begin{array}{ll}\text { Je tombes } & \text { sur le sol } \\ 1 \mathrm{sg} . \quad \text { caer.1SG.PRS.IND. } & \text { sobre el suelo } \\ \text { ('Me caigo al suelo') } & \end{array}$

(28) Je tombe la chemise sur le sol

1sg. caer.1SG.PRS.IND. la camisa sobre el suelo

('Caigo la camisa al suelo')

Estas frases muestran que los tres verbos pueden desarrollar un objeto directo aunque el significado original fuera intransitivo. Mientras que (23-27) son perfectamente estándares, (28) no se acepta por la norma y pertenece al francés vernáculo. Téngase en cuenta que todos ellos son inacusativos y verbos de logro; además, tomber ('caer') coincide con el fenómeno en español.

A pesar de la relevancia de la semántica para la labilidad, la sintaxis también se ha revelado importante a este respecto. Kulikov (1999a, 1999b, 2003) o Letuchiy (2004) han apuntado que ciertas lenguas o en ciertos estadios de una lengua, la labilidad se ve favorecida por el tiempo, el modo o incluso la proximidad fonética de verbos estrechamente relacionados (como es el caso del estonio: Kehayov \& Vihman 2014). De hecho, el comportamiento de entrar como lábil en el español peninsular occidental actual sigue la oposición perfectivo-imperfectivo más que la semántica del sujeto u objeto. Karantzola \& Lavidas (2014) incluso han encontrado que ciertas construcciones con un sintagma nominal neutro en posición posverbal han motivado la labilidad en griego.

En cualquier caso, para Letuchiy (2009), la motivación para la existencia de la labilidad surge de la necesidad semántica de unificar bajo un mismo lexema la denotación de dos situaciones o entidades muy próximas, independientemente de lo que las diferencie. Por tanto, la labilidad es un tipo de polisemia, pues el factor crucial para esta es la proximidad entre rasgos semánticos y sintácticos de ambas situaciones, más que la diferencia en sus valencias o transitividad. De la misma opinión es Haspelmath (1993), quien define la alternancia causativa-incoativa como un par de verbos que básicamente denotan la misma situación (generalmente, un cambio de estado) y que difieren tan solo en el hecho de que el verbo 
causativo incluye la participación de un agente y el incoativo carece de ella y presenta la situación como espontánea. En su estudio lingüístico, Haspelmath advierte que la estrategia de la labilidad (dentro de la categoría de alternancia no directa propuesta por Nedjalkov 1969) es la menos frecuente de todas y suele aparecer en inglés.

En sintonía con esta teoría, entrar, quedar y caer serían verbos polisémicos que denotarían situaciones muy próximas, sin tener en cuenta el número de participantes, su volición o agentividad. Es más, si los mapas 8,9 y 11 se comparan, observamos el desplazamiento de tirar por caer a prácticamente cualquier contexto, siendo polisémico de acuerdo con las tesis de Letuchiy (2009). De acuerdo con esto, los informantes que expresan caer para acciones agentivas también lo hacen con sujetos involuntarios y no animados. El verbo quedar aparece en lecturas de bajo control o escasa volición y, posteriormente, extiende su polisemia a contextos volitivos. Asimismo, si entrar se fomenta en lecturas télicas, surge también en las atélicas.

Las investigaciones que se han realizado han certificado que la labilidad se suele producir convirtiendo el verbo transitivo en intransitivo. Los mejores ejemplos se hallan en inglés (Visser 1970; McMillion 2006) o incluso en latín (Gianollo 2014). En cambio, los lexemas del español afectados por este proceso son verbos intransitivos que terminan convirtiéndose en transitivos. Este recorrido de intransitivo a transitivo apenas se documenta y no suele darse universalmente. De hecho, Letuchiy (2015) investiga el desarrollo de la labilidad en el ruso moderno y reconoce que todos los verbos que han experimentado este proceso son transitivos que terminaron siendo intransitivos también. Tan solo encuentra un verbo (kapat / kapnut: 'caer / tirar') que transita de intransitivo a transitivo. La escasez de ejemplos con respecto a la conversión a transitivos plantea la cuestión sobre los requisitos para la transitivización. Un vistazo a la bibliografía nos indica que la causativización y la transitivización están íntimamente ligadas.

\subsection{Causativización y transitivización}

Como se ha argumentado a lo largo del presente artículo, la semántica es crucial en la construcción sintáctica causativa, un hecho apoyado por muchos tipólogos. Por ejemplo, Comrie (1981), Comrie \& Polinsky (1993), Shibatani (1976) y Aikhenvald \& Dixon (2000) proponen un continuum causativo que sugiere que la probabilidad de causativizar un verbo depende de las siguientes características: animacidad del sujeto, volición del agente, control del sujeto, prominencia y grado del causante sobre lo causado. Givón $(1976 ; 2001)$ está de acuerdo con estos parámetros y añade la distinción entre causa directa e indirecta. Según el autor, cuanto más directa es una causa, mayor probabilidad de encontrar una estrategia léxica; por el contrario, cuando menos directa sea, mayor posibilidad de que se emplea una estrategia analítica. Estas diferencias semánticas favorecen 
un tipo de marca de caso en diversas lenguas. Como ejemplo, el húngaro puede tener un paciente marcado en acusativo o instrumental, según el control del causante sobre lo causado. Así, se dice que el húngaro sigue un continuum [instrumental $>$ dativo $>$ acusativo] para expresar dicho control. Los acusativos expresan mayor control frentes a los instrumentales que, por lo general, se interpretan como carentes de volición y control (véase 29-30, tomados de Hetzron 1976).
Az ápolóno
minden
nap egy órát
sétáltata
ot
La enfermera todos
día una hora.ACC. hacer:caminar
él.ACC.
('La enfermera le hizo caminar una hora al día')

$\begin{array}{llll}\text { Az orvos minden nap egy órát } & \text { sétáltatott } & \text { vele } \\ \text { El médico todos día una hora.ACC. } & \text { hacer:caminar } & \text { él.INSTR. } \\ \text { ('El médico le hizo caminar una hora al día') [como prescripción] }\end{array}$

Asimismo, este autor pone de manifiesto que hay una distinción entre el agente y el autor de una causa: mientras la autoría no implica intención, la agentividad sí. Ramchand (2011) ha descubierto el mismo patrón en hindi y urdu y Daniel et al. (2012) aseguran que en agul, una lengua caucásica, se selecciona una construcción causativa perifrástica para expresar menor control sobre lo causado y se elige una estrategia léxica si hay más control. Kim (2012) afirma que, en coreano, el causante no es lo mismo que el agente y la marca de caso de una construcción causativa depende de la volición del sujeto y la afectación del objeto.

El rasgo más notable en el caso del español recae en la transitivización de los verbos intransitivos. Hopper \& Thompson (1980) comparten un artículo célebre sobre los factores que favorecen la aparición de un verbo transitivo. Según ellos, algunas de estas condiciones son la agentividad, el aspecto, la volición, la kinesis o la afectación. Cuanto más fuertes sean estos rasgos, mayor probabilidad de hallar un verbo transitivo. En base a las ocurrencias recogidas, es obvio que la caída del lexema transitivo normativo se fomenta en lecturas de escasa o nula agentividad (11), de falta de volición (7-10) o de poca afectación del paciente (7-8). Cuanto más intencionado, animado (16-18) o télico (19-20), mas probable es que los informantes elijan los lexemas transitivos estándares. El par léxico meter-entrar es el que mejor ejemplifica el factor de telicidad, pues los informantes han distinguido entre (31) y (32).

(31) La chica mete la botella en el bolso

(32) La chica abre la puerta y entra la silla en el despacho

Mientras que (31) muestra una acción télica (los informantes la han producido cuando la acción ya se ha completado), en (32) la silla es arrastrada a la oficina. Esto quiere decir que mientras (31) sucede en un instante, (32) necesita un tiempo 
más prolongado para completarse, por lo que los informantes expresan el desarrollo de la acción y la falta de conclusión mediante el verbo intransitivo. Además, como hemos apuntado al igual que Montero (2006), el empleo de caer, quedar o entrar como transitivos surgen en las lecturas semánticas descritas porque los verbos transitivos existentes (tirar, dejar y meter) resultan demasiado transitivos para expresar los matices semánticos comentados.

En el caso del español, como carece de una flexión rica de caso (excepto en sus pronombres), las distinciones semánticas de verbos estrechamente relacionados necesitan codificarse por otros medios. En otras palabras, como los verbos transitivos estándares son demasiado transitivos (siguiendo la escala de transitividad de Hopper \& Thompson 1980, 1982) (poseen un sujeto agentivo, normalmente humano y un paciente afectado que suele experimentar un cambio de estado), el empleo de un intransitivo como transitivo implica la noción de un agente involuntario, incapaz de controlar la situación producida por el cambio de estado (curiosamente, Letuchiy 2010 defiende que los verbos lábiles suelen surgir en baja transitividad). Es por eso que hemos hallado de los mismos informantes oraciones como (34) si la acción no se ha realizado adrede, y oraciones como (33) si la acción ha sido intencionada.

(33) La chica ha cogido el vaso y lo ha tirado

(34) La chica se ha tropezado y ha caído el vaso

La frase (33) tiene una construcción transitiva típica y, por tanto, se prefiere el verbo tirar y (34) expresa falta de volición o intención, pero el verbo intransitivo ha surgido para transformar al participante que ha llevado a cabo la acción en el sujeto de la oración. El vaso sigue siendo el paciente, pero la chica es la autora. Por tanto, los verbos caer, quedar y entrar se caracterizan por ser capaz de elegir dos tipos de sujeto (agentivo o no), dependiendo del grado de control sobre la actividad dada.

\subsection{Intransitividad escindida}

Ya hemos hecho referencia al hecho de que la labilidad en el español peninsular occidental es del tipo $P$-alignment. Aunque el $P$-alignment se ha relacionado con las lenguas ergativas y ha habido muchos estudios sobre cambios en las valencias de la evolución del latín a las lenguas romance e incluso del francés antiguo al moderno (Heidinger 2014; Gianollo 2014), en todos estos casos es el verbo transitivo el que puede usarse intransitivamente (es más, solo Larjavaara 2000 y Bilous 2012 han dado cuenta del uso transitivo de tomber, 'caer', en ciertos contextos de algunas variedades del francés). Este fenómeno en el caso del español extiende una valencia intransitiva a una transitiva. Lo que es más: convierte los inacusativos pero no los inergativos en transitivos. 
La divergencia entre inacusativos e inergativos se ha denominado inacusatividad escindida. De hecho, cando analizamos el comportamiento de la labilidad en los ejemplos recogidos, nos damos cuenta de que todos los verbos afectados son inacusativos. Esto resulta de vital importancia en el comportamiento lingüístico. En principio, los verbos inacusativos carecen de control por parte del sujeto (el sujeto se comporta más como un paciente que como un agente) (Dowty 1991; Ackerman \& Moore 2001), mientras que los verbos inergativos poseen un sujeto volitivo y, por ende, un agente. Para Perlmutter (1978), los verbos inacusativos tienen sujetos con rasgos similares a los de los objetos de los transitivos. La distinción en la sintaxis en base a la semántica del sujeto recuerda al patrón de alineamiento ergativo-absolutivo. La diferencia esencial entre las lenguas ergativo-absolutivas y las nominativo-acusativas yace en la forma en la que marcan la relación entre sujeto y objeto. Así, una lengua ergativa posee una marca de caso específica para el sujeto de una transitiva (A) y una distinta para los sujetos de las intransitivas (S), los pacientes o los objetos (O) (Dixon 1994); por el contrario, las lenguas acusativas unen $\mathrm{S}$ y A bajo la misma etiqueta (el sujeto) y $\mathrm{O}$, en una distinta. Sin embargo, como Dixon afirma, no hay lenguas puramente acusativas o puramente ergativas, ya que la mayoría combina ambos patrones. Este comportamiento lingüístico se ha denominado ergatividad escindida e incluso el orden de palabras en español aplica esta distinción: los verbos inacusativos en español suelen colocar el sujeto tras el verbo, como si fueran un tipo de objeto o paciente en lugar de un verdadero sujeto (Mendikoetxea 1999). Comparemos los siguientes ejemplos:

(35) El atleta corre cuatro horas

(36) Se han caído las hojas de los árboles

Las frases (35) y (36) muestran un verbo intransitivo con distintos tipos de sujeto. Mientras que (35) se caracteriza por un verbo inergativo porque posee un agente, (36) presenta un verbo inacusativo que envía el sujeto (en este caso, el paciente) a una ubicación que prototípicamente ostenta el objeto o paciente. Van Valin (1990) o Merlan (1985) apuntan que este rasgo se define mejor como intransitividad escindida, ya que estas lenguas se caracterizan por mostrar diferenciación en su sintaxis según la naturaleza del verbo intransitivo, más que en la distinción constante entre agentivo o no agentivo en todo su comportamiento lingüístico. Esta escisión se manifiesta en georgiano o italiano, en concreto en verbos de logro o lexemas inacusativos con sujetos pacientes (Harris 1982; Hewitt 1987; Van Valin 1990). Asimismo, el tiempo, el aspecto y el modo son también importantes, pues, por ejemplo, los perfectos en holandés presentan dos auxiliares, dependiendo de la telicidad o atelicidad; el védico (Kulikov 1999a, 1999b, 2003) y el griego (Karantzola \& Leonidas 2014) están sometidos al modo, el tiempo y, en el último caso, incluso al género del sintagma nominal dependiente del verbo. El acehnese 
y las lenguas tsova-tush también tienen en cuenta la agentividad para desarrollar la intransitividad escindida (Durie 1985).

El italiano es una de las lenguas más investigadas con respecto a la intransitividad escindida. Según Burzio (1981, 1986), esta lengua aplica la escisión en la selección del auxiliar en los perfectos. Comparemos los ejemplos (37-39), tomados de Van Valin (1990).
Angela è
arrivata
Angela ser.3SG.PRS.IND.
llegar.PCP.SG.FEM.

('Angela ha llegado')

Angela è

morta

Angela ser.3SG.PRS.IND.

morir.PCP.SG.FEM.

('Angela ha muerto')
Angela ha
ballato
con loro
Angela haber.3SG.PRS.IND. bailar.PCP. con ellos
('Angela ha bailado con ellos')

Mientras (39) es un sujeto agentivo y ha de concordar con avere ('haber'), los dos primeros solo pueden formar el perfecto con essere ('ser') porque son involuntarios, pacientes. Asimismo, hay verbos que alternan entre essere y avere, dependiendo de la agentividad o volición, como muestran (40-41).
(40) Ho
corso
durante un'ora
Haber.1SG.PRS.IND. correr.PCP. durante una hora
('He corrido una hora')
(41) Sono
corso durante un'ora
Ser.1SG.PRS.IND. correr.PCP.SG.MASC. durante una hora ('He corrido una hora')

La diferencia entre (40) y (41) radica en el grado de volición o control de la situación. Mientras que (40) es una acción completamente agentiva, (41) puede implicar que el sujeto se ha sentido relativamente obligado a ello.

Pero el español también presentaba este patrón en época medieval. Según Elvira (2001), el español medieval formaba tiempos perfectos tanto con ser como con haber. La elección por uno u otro se basaba en los mismos patrones que el italiano sigue hoy día (42-43).

(42) De un día es llegado antes el rey don Alfons

(43) El fuego quando es encendido sin viento

Los ejemplos (42-43) muestran que, hasta casi el final de la Edad Media, los verbos inacusativos necesitaban el verbo ser para los tiempos perfectos. Este patrón desapareció hace cinco siglos y ni siquiera se atestigua en el español dialectal. 
Está de más decir que es precipitado afirmar que el español tiene una tendencia hacia la ergatividad. De hecho, como Dixon (1994), Creissels (2008) o Elvira (2012) dicen, no hay lenguas puramente ergativas mientras que solo unas pocas lenguas acusativas poseen un comportamiento puramente acusativo, sin influencias ergativas. Además, Elvira (2012) recuerda el hecho de que el español es heredero de una lengua bastante acusativa (latín) que incluso exhibía varios patrones ergativos, como los verbos deponentes (Bassols de Climent 1956; Baños Baños 2009). No obstante, Klimov (1977) ha sostenido que las lenguas suelen seguir un desarrollo específico en su alineamiento. Si una lengua es principalmente ergativa o muestra múltiples patrones ergativos, sufrirá una serie de estadios que la acerquen a la acusatividad. Según esto, el indoeuropeo presentaba una gran cantidad de particularidades ergativas (Laroche 1962; Meillet 1931) que se redujeron en latín (Cennamo 2009) y que fueron todavía menos en el paso a las lenguas romances actuales (Lehmann 1985). En el caso del español, este ha ido eliminando de manera gradual las particularidades sintácticas que resaltaban los patrones de intransitividad o ergatividad escindidas (Elvira 2012). La única característica que aún permanece en el estándar es la colocación de los sujetos inacusativos en posiciones de objeto.

\subsection{Ergatividad escindida}

Aunque el español estándar muestra intransitividad escindida, el español peninsular occidental acumula una serie de rasgos lingüísticos que lo aproximan a la ergatividad. La distinción entre el tipo de sujeto semántico no solo se aplica a frases intransitivas, sino también a los pronombres átonos, las marcas de reflexivo y la estrategia de la labilidad.

Este dialecto se caracteriza por una serie de particularidades basadas en la animacidad, agentividad y volición que difieren del estándar. El tema más estudiado es el leísmo, laísmo, loísmo. El español estándar cuenta con la marca de caso para seleccionar el clítico. En otras palabras, la opción por el clítico se basa en el hecho de que el objeto sea acusativo o dativo, masculino o femenino y singular o plural (44-49).

(44) La veo [a la chica]

(45) Les gusta el chocolate [a ellas]

(46) El fuego los quemó [los bosques]

(47) La leche, la bebo

(48) El hombre lo tira a la papelera [el cigarro]

(49) El viento lo tira al suelo [el papel] 
El español peninsular occidental, por el contrario, se centra en la animacidad del sujeto y del objeto e incluso en la oposición contable e incontable (50-55) (Fernández-Ordóñez 1999, 2006, 2007).

(50) La veo [a la chica]

(51) Las gusta el chocolate [a ellas]

(52) El fuego les quemó [los bosques]

(53) La leche, lo bebo

(54) El hombre lo tira a la papelera [el cigarro]

(55) El viento le tira al suelo [el papel]

Mientras que (44-49) han elegido un clítico según el caso, el género y el número, (50-55) confunden los clíticos estándares mezclando el acusativo y el dativo según la animacidad del objeto y el sujeto. Téngase en cuenta que (51), a pesar de que tiene un sujeto no animado, muestra un objeto humano y da importancia al género y número más que al parámetro del caso. Por el contrario, (52) muestra un sujeto no humano más un objeto no humano y por eso selecciona un dativo en vez de un acusativo. Lo mismo se aplica a (53-55), que eligen un clítico distinto en función de la semántica del sujeto. La frase (53) es una muestra de la distinción entre contable e incontable: aunque leche es femenino, gran parte del español peninsular occidental produce un neutro.

Pero los pronombres átonos no son el único ejemplo de esta particularidad según la volición, animacidad o agentividad (es cierto, no obstante, que el leísmo, laísmo, loísmo se ha extendido a zonas del español central, sobre todo los dos primeros). Cada vez más estudios llaman la atención sobre el incremento de reflexivos en el español peninsular occidental en oraciones en las que el sujeto carece de volición o agentividad (De Benito 2015). Comparemos (56-57).

(56) Ayer me soñé que me caía de un precipicio

Hay que esperar a que la fruta se madure

La frase (56) muestra que el reflexivo se produce porque el sujeto no puede decidir o controlar si sueña o no. El sujeto simplemente sueña. De igual manera, (57) demuestra que la fruta no puede controlar si madura o no. Esta estrategia es imposible en español estándar y no se documenta fuera del área occidental peninsular.

Aunque hemos desechado el estudio de Jiménez Fernández \& Tubino Blanco (2014) a propósito de la extensión de la labilidad en el andaluz por los motivos expuestos, hemos de reconocer que aciertan en apuntar que existe una productividad de hacer ciertos verbos reflexivos. Sin embargo, su análisis se refiere a toda Andalucía y, aunque este patrón se atestigua en el andaluz occidental (RAE 
2009), los autores pasan por alto dividir Andalucía en dos bloques muy reconocibles. Es la parte oeste la que puede desarrollar reflexivos y, como occidental, a veces adopta los rasgos lingüísticos que se documentan en el español peninsular occidental. Asimismo, sostienen que el uso del reflexivo (se) está relacionado con la codificación el origen del evento más que con la falta de agentividad. Sus ejemplos (reproducidos en 58-60) serían una prueba de este hecho, pero las ocurrencias que proporcionan no son apropiadas para su justificación.

(58) Juan se ha bajado la bicicleta a la calle

(59) Juan se ha subido los juguetes a casa

(60) Juan se ha entrado las sillas en casa

Los autores, en las oraciones (58-60) (una de las cuales incluye la causativización de entrar), relacionan el empleo del reflexivo se a la causativización y alegan que los tres ejemplos se atestiguan en el andaluz. De nuevo, el andaluz se puede dividir en dos, con claras diferencias entre oeste y este según la morfosintaxis. Además, (58-60) se atestiguan en todo el español peninsular y son perfectamente estándares. En nuestra opinión, los autores no reconocen estos reflexivos como dativos posesivos (bastante frecuente en español (Davis 1968; Dumitrescu 1990)), por lo que (58-60) se pueden sustituir perfectamente por (61-63).

(61) Juan ha bajado su bicicleta a la calle

(62) Juan ha subido sus juguetes a su casa

(63) Juan ha entrado sus sillas en casa

Así, los ejemplos de Jiménez Fernández \& Tubino Blanco (2014) no toman en cuenta la productividad de los reflexivos en los verbos inacusativos, es decir, en verbos en los que el sujeto es el autor y no el agente. Téngase en cuenta que este rasgo vernáculo es similar a la estrategia estándar ejemplificada en (3), en la que el verbo admite el reflexivo precedido de un experimentante para expresar falta de volición o control del autor.

En conclusión, en lo que respecta a la labilidad en este dialecto, solo hemos podido proporcionar un primer panorama de los matices semánticos que influyen en el fenómeno, pero la investigación debería ampliarse, con el foco en otros parámetros sintácticos, como el tiempo, modo o aspecto, ya que bastantes lenguas, como el hindi-urdu, seleccionan la ergatividad solo en ciertos tiempos (Garrett 1990; Kulikov 1999b).

\section{Conclusiones}

El fenómeno de la causativización (labilidad) que se atestigua en el español peninsular occidental, consistente en la extensión de un verbo intransitivo a una lectura transitiva, (en concreto de caer, quedar y entrar), se sigue manteniendo 
aunque su difusión espacial ha decrecido drásticamente en comparación con las descripciones de las que disponíamos hasta ahora. Según el trabajo de campo realizado, actualmente existe mucha presión hacia la estandarización, la cual ha desplazado este fenómeno a las áreas más suroccidentales. Asimismo, la distribución de entrar es mayor que la de quedar, la cual está incluso más extendida que la de caer. De esta manera, parece existir un continuum jerárquico en el que los informantes que se caracterizan por el uso de caer como transitivos lo producen en quedar y entrar con objeto directo también. Además, los hablantes que usas estos verbos en oraciones con un agente voluntario también lo hacen en oraciones con un sujeto no humano y uno involuntario. De igual manera, si lo usan en lecturas télicas, también recurren a la labilidad en oraciones atélicas.

La labilidad depende de una serie de factores semánticos que comprenden la agentividad, el control, la volición o la telicidad. En lugar de los cambios morfológicos atestiguados en otras lenguas, el español escoge transitivizar el lexema intransitivo porque carece de flexión nominal. Como el español cuenta con verbos muy transitivos que denotan acciones estrechamente relacionadas, los matices semánticos se materializan mediante la labilidad.

Si bien esta investigación necesite extenderse a todo tipo de hablantes, de acuerdo con su perfil social, y recoger un mayor número de ocurrencias así como de matices semánticos y sintácticos, este panorama refleja que el factor semántico es vital a la hora de producir el fenómeno. A priori, la zona alrededor de Badajoz es la que más produce el fenómeno, ya que ha esparcido el verbo intransitivo incluso a lecturas volitivas, pero la particularidad vernácula recorre la ruta de la plata romana como camino de difusión por el oeste de España.

Aunque el español ha mostrado a lo largo de su historia patrones de intransitividad escindida heredados del latín, su tendencia a ser una lengua completamente nominativo-acusativa se evidencia claramente. El único modelo mixto que hallamos actualmente es la colocación de sujetos inacusativos en posiciones de objeto, pero la elección de ser como auxiliar de los tiempos perfectos ya no existe y las particularidades que conviven en ciertas áreas dialectales no se han generalizado.

Por el contrario, el bloque que constituye el español peninsular occidental sí que muestra un patrón lingüístico que se puede definir mejor como ergatividad escindida. En lugar de emplear los verbos inacusativos de distinta manera (lo cual hace), ha desarrollado varias estrategias para diferenciar mediante la sintaxis entre participantes volitivos o agentivos de los no volitivos o no agentivos. Estas estrategias se representan con claridad en la selección del clítico, el fenómeno de la labilidad, la colocación de los sujetos de los inacusativos en posiciones de objeto así como el recurso de los reflexivos. Todos estos comportamientos se incluyen en las numerosas particularidades que este bloque geográfico comparte: desde características fonéticas (velarización de /n/ final), a morfológicas (el uso 
de vos medieval en lugar de os como clítico de segunda persona de plural) y sintácticas (la tendencia a expresar el futuro mediante tiempos de presente en lugar de los tiempos sintéticos estándares).

\section{Referencias}

Ackerman, Farrell \& John Moore. 2001. Proto-properties and grammatical encoding. Stanford: CSLI Publications.

Aikhenvald, Aleksandra \& Robert Dixon (eds). 2000. Changing valency. Case studies in transitivity. Cambridge: Cambridge University Press.

ALCyL: véase Alvar, Manuel. 1999.

ALEANR: véase Alvar, Manuel. 1979-1983.

ALEC-MAN: véase García Mouton, Pilar \& Francisco Moreno Fernández. 19881994.

Alvar, Manuel. 1979-1983. Atlas lingüistico y etnográfico de Aragón, Navarra y Rioja (ALEANR). Zaragoza: CSIC.

Alvar, Manuel. 1996. Manual de dialectología hispánica. Barcelona: Ariel.

Alvar, Manuel. 1999. Atlas lingüistico de Castilla y León. Valladolid: Junta de Castilla y León.

Ariza, Manuel. 2008. Estudios sobre el extremeño. Cáceres: Universidad de Extremadura.

Baños Baños, José Miguel. 2009. Sintaxis del latín clásico. Madrid: Liceus.

Bassols de Climent, Mariano. 1956. Sintaxis latina. Madrid: CSIC.

Bilous, Rostyslav. 2012. Transitivity revisited: an overview of recent research and possible solutions. In Proceedings of the 2012 annual conference of the Canadian Linguistic Association, 1-14.

Burzio, Luigi. 1981. Intransitive verbs and Italian auxiliaries. Cambridge: MIT.

Burzio, Luigi. 1986. Italian syntax. Dordrecht: Reidel.

Cano, Rafael. 2004. Historia de la lengua española. Barcelona: Ariel.

Cennamo, Michela. 2009. Argument structure and alignment variations and changes in Late Latin. In The role of semantic, pragmatic and discourse factors in the development of case, 307-346, eds. Jóhanna Barddal \& Shobhana Chelliah. Ámsterdam: John Benjamins.

Comrie, Bernard. 1981. Language universals and linguistic typology, syntax and morphology. Oxford: Blackwell.

Comrie Bernard. \& Maria Polinsky (ed.). 1993. Causatives and transitivity. Ámsterdam / Filadelfia: John Benjamins Publishing Company.

COSER: véase Fernández-Ordóñez, Inés. 1988-2016.

Creissels, Denis. 2008. Direct and indirect explanations of typological regularities: the case of alignment variations. Folia linguistica 42: 1-38.

Creissels, Denis. 2014. P-liability and radical P-alignment. Linguistics 52: 911-944. 
Daniel, Michael, Timor Maisak \& Solmaz Merdanova. 2012. Causatives in Agul. In Argument structure and grammatical relations, 55-113, ed. Masayoshi Shibatani. Ámsterdam / Filadelfia: John Benjamins.

Davis, Cary. 1968. The indirect object of possession in Spanish. The USF Language Quarterly 1968: 1-6.

De Benito, Carlota. 2015. Las construcciones con se desde una perspectiva variacionista y dialectal. Madrid: Universidad Autónoma de Madrid.

Dixon, Robert. 1994. Ergativity. Cambridge: Cambridge University Press.

Dowty, David. 1991. Proto-roles and argument selection. Language 67: 547-619.

Dumitrescu, Domnita. 1990. El dativo posesivo en español y rumano. Revista Española de Lingüística 20: 403-429.

Durie, Mark. 1985. A grammar of Acehnese. Dordrecht: Foris.

Elvira, Javier. 2001. Intransitividad escindida en español: el uso auxiliar de ser en español medieval. Estudios de lingüística 15: 201-245.

Elvira, Javier. 2012. Construcciones y significado: aspectos diacrónicos de la transitividad en español. In Corrientes de estudio en semántica y pragmática históricas. In Corrientes de estudio en semántica y pragmática históricas, 1-28, ed. Ricardo Maldonado. Madrid: Instituto Menéndez Pidal.

Fernández-Ordóñez, Inés. 1988-2016. Corpus Oral y Sonoro del Español Rural (COSER). http://www.uam.es/coser/.

Fernández-Ordóñez, Inés. 1999. Leísmo, laísmo y loísmo. In Gramática descriptiva de la lengua española, 1317-1397, eds. Ignacio Bosque \& Violeta Demonte. Madrid: Espasa.

Fernández-Ordóñez, Inés. 2006. Del Cantábrico a Toledo: el "neutro de materia" hispánico en un contexto románico y tipológico I. Revista de Historia de la Lengua Española 1: 67-118.

Fernández-Ordóñez, Inés. 2007. Del Cantábrico a Toledo: el "neutro de materia" hispánico en un contexto románico y tipológico II. Revista de Historia de la Lengua Española 2: 29-81.

Fernández-Ordóñez, Inés. 2011. La lengua de Castilla y la formación del español. Madrid: Espasa.

Frago, Juan Antonio. 1993. Historia de las hablas andaluzas. Madrid: Arco Libros.

García Mouton, Pilar \& Francisco Moreno Fernández. 1988-1994. Atlas Lingüístico (y etnográfico) de Castilla-La Mancha. http://www2.uagh.es/alecman.

García Mouton, Pilar. 1994. Lenguas y dialectos de España. Madrid: Arco Libros. Garrett, Andrew. 1990. The origin of NP split ergativity. Language 66: 261-296.

Gianollo, Chiara. 2014. Labile verbs in Late Latin. Linguistics 52: 945-1002.

Gilquin, Gaëtanelle. 2010. Corpus, cognition and causative constructions. Ámsterdam / Filadelfia: John Benjamins.

Givón, Talmy. 1976. The syntax of causative constructions: cross-language similarities and divergences. In Syntax and semantics. The grammar of causative constructions, 80-120, ed. Masayoshi Shibatani. Nueva York: Academic Press.

Givón, Talmy. 2001. Syntax. Ámsterdam / Filadelfia: John Benjamins. 
Harris, Alice. 1982. Georgian and the unaccusative hypothesis. Linguistics 58: 290306.

Haspelmath, Martin. 1993. More on the typology of inchoative/causative verb alternations. In Causatives and transitivity, 87-121, eds. Bernard Comrie \& Maria Polinsky. Ámsterdam / Filadelfia: John Benjamins.

Heidinger, Steffen. 2014. The persistence of labile verbs in the French causativeanticausative alternation. Linguistics 52: 1003-1024.

Hetzron, Robert. 1976. On the Hungarian causative verb and its syntax. In The grammar of causative constructions, 371-398, ed. Masayoshi Shibatani. Nueva York: Academic Press.

Hewitt, George. 1987. Georgian: ergative or active? Lingua 71:319-340.

Hopper, Paul \& Thompson, Sandra. 1980. Transitivity in grammar and discourse. Language 56: 251-299.

Hopper, Paul \& Sandra Thompson (ed.). 1982. Syntax and semantics. Studies in transitivity. Nueva York: Academic Press.

Jiménez Fernández, Ángel \& Mercedes Tubino Blanco. 2014. Variación sintáctica en la causativización léxica. Revista española de lingüistica 44: 7-38.

Karantzola, Eleni \& Nikolaos Lavidas. 2014. On the relation between labilisations and neuter gender: evidence from Greek diachrony. Linguistics 52: 1025-1059.

Kehayov, Petar \& Virve Vihman. 2014. The lure of lability: a synchronic and diachronic investigation of the labile pattern in Estonian. Linguistics 52: 1061-1105.

Kim, Hee-Su. 2012. Transitives, causatives and passives in Korean and Japanese. In Argument structure and grammatical relations, 241-255, ed. Masayoshi Shibatani. Ámsterdam / Filadelfia: John Benjamins.

Klimov, Georgij. 1977. Tipologija jazykovaktivnogo stroja. Moscú: Nauka.

Kulikov, Leonid. 1999a. May he prosper in offspring and wealth: a few jubilee remarks on the typology of labile verbs and Sanskrit púsyati 'prosper; makes prosper'. In Tipologija i teorija jazyka: at opisanija k ob”'jasneniju K 60-letiju A. E. Kibrika, 224-244, eds. Ekaterina Rakhilina \& Yakov Testelets. Moscú: Jazyki russkoj kul'tury,

Kulikov, Leonid. 1999b. Split causativity: remarks on correlations between transitivity, aspect and tense. In Tense, aspect, transitivity and causativity. Essays in honour of Vladimir Nedjalkov, 21-43, eds. Werner Abraham \& Leonid Kulikov. Ámsterdam / Filadelfia: John Benjamins.

Kulikov, Leonid. 2003. The labile syntactic type in a diachronic perspective: the case of Vedic. Journal of linguistics 26: 93-112.

Kulikov, Leonid. \& Nikolaos Lavidas. 2014. Typology of labile verbs: focus on diachrony. Linguistics 52: 871-877.

Lara, Víctor. 2012. Ustedes instead of vosotros and vocês instead of vós: an analysis through the Linguistic Atlas of the Iberian Peninsula (ALPI). Dialectologia Special Issue 3: 57-93. 
Lara, Víctor. 2016. La expresión del futuro en las lenguas romances de la Península Ibérica. Boletín de la Real Academia Española XCVI (Cuaderno CCCXIV): 529558.

Larjavaara, Meri. 2000. Présence ou absence de l'objet: limites du possible en français. Helsinki: Academia Scientirum Fennica.

Laroche, Emmanuel. 1962. Un ergative en indo-europeen d'Asie Mineure. Bulletin de la Société de linguistique de Paris 57: 23-43.

Lehmann, Christian. 1985. Ergative and active traits in Latin. In Relational gramar, 243-267, ed. Frans Plank. Berlín: Mouton de Gruyter.

Letuchiy, Alexander. 2004. Lability of verbs and its relations to verb meaning and argument structure (based on data from Indo-European, Arabic, Turkish and other languages). Vortrag beim LENCA-2-Symposium an der Universität Kasan, 11.14.5.2004: http://www.ksu.ru/conf/LENCA-2/187.rtf (último acceso: 20 de diciembre de 2016).

Letuchiy, Alexander. 2009. Towards a typology of labile verbs: lability versus derivation. In New challenges in typology: transcending the borders and refining the distinctions, 247-268, eds. Patience Epps \& Alexandre Arkhipov. Berlín: Mouton de Gruyter.

Letuchiy, Alexander. 2010. Lability and spontaneity. In Transitivity: form, meaning, acquisition and processing, 237-255, eds. Patrick Brandt \& Marco García. Ámsterdam / Filadelfia: John Benjamins.

Letuchiy, Alexander. 2015. Historical development of labile verbs in modern Russian. Linguistics 53: 611-647.

McMillion, Alan. 2006. Labile verbs in English: their meaning, behaviour and structure. Estocolmo: University of Stockholm.

Meillet, Antoine. 1931. Essai de chronologie des langues indo-européennes, la theorie du feminine. Bullentin de la Société de linguistique de Paris 32: 1-28.

Mendikoetxea, Amaya. 1999. Construcciones inacusativas y pasivas. In Gramática descriptiva de la lengua española, 1575-1630, eds. Ignacio Bosque \& Violeta Demonte. Madrid: Espasa.

Menéndez Pidal, Ramón. 2005. Historia de la lengua española. Madrid: Instituto Menéndez Pidal.

Merlan, Francesca. 1985. Split intransitivity: functional oppositions in intransitive inflection. In Grammar inside and outside the clause, 324-362, eds. Johanna Nichols \& Anthony Woodbury. Cambridge: Cambridge University Press.

Mondéjar, José. 1991. Dialectología andaluza. Granada: Don Quijote.

Montero, Pilar. 2006. El extremeño. Madrid: Arco Libros.

Narbona, Antonio. 2003. El español hablado en Andalucía. Sevilla: Ariel.

Nedjalkov, Vladimir. 1969. Nekotorye verojatnostnye universalii v glagol'nom slovoobrazonavii. In Jazykovye universalii i lingvističeskaja tipologija, 106-114, ed. Igor Vardul. Moscú: Nauka. 
Nerbonne, John, Rinke Colen, Charlotte Gooskens, Peter Kleiweg \& Therese Leinonen. 2010. Gabmap - A Web Application for Dialectology. Groningen: University of Groningen. http://www.gabmap.nl/.

Nunes, José Joaquim. 1945. Compêndio de gramática histórica portuguesa. Lisboa: Livraria Clássica Editora.

Penny, Ralph. 2004. Gramática histórica del español. Barcelona: Ariel.

Perlmutter, David. 1978. Impersonal passives and the unaccusativity hypothesis. In Proceedings of the 4th Annual meeting of the Berkeley linguistic society, 157189. Chicago: Berkeley University.

Ramchand, Gillian. 2011. Licensing of instrumental case in Hindi / Urdu causatives. Nordlyb 38 : 49-85.

Real Academia Española \& Asociación de Academias de la Lengua Española. 2009. Nueva gramática de la lengua española. Madrid: Espasa.

Said, Manoel. 1931. Gramática histórica da língua portuguesa. Río de Janeiro: Livraria Académica.

Shibatani, Masayoshi (ed.). 1976. Syntax and semantics. The grammar of causative constructions. Nueva York: Academic Press.

Van Valin, Robert. 1990. Semantic parameters of split intransitivity. Language 66: 221-260.

Visser, Fredericus. 1970. A historical syntax of the English language. Leiden: Brill. Wheeler, Max, Alan Yates \& Nicolau Dols. 1999. Catalan: a comprenhensive grammar. Londres: Routledge.

Wolfram, Wolfram \& Natalie Schilling-Estes. 2003. Dialectology and Linguistic Diffusion. In The Handbook of Historical Linguistics, 713-735, eds. Brian Joseph \& Robert Janda. Malden: Blackwell.

Zamora Vicente, Alonso. 1970. Dialectología española. Madrid: Gredos.

Victor Lara·viktoresc@hotmail.com·Universität Bern·SwITZERLAND 